\title{
Acute type A aortic dissection complicated by aortic regurgitation: Composite valve graft versus separate valve graft versus conservative valve repair
}

\author{
David T. Lai, FRACS \\ D. Craig Miller, MD \\ R. Scott Mitchell, MD \\ Philip E. Oyer, MD, PhD \\ Kathleen A. Moore, BS \\ Robert C. Robbins, MD \\ Norman E. Shumway, MD, PhD \\ Bruce A. Reitz, MD
}

From the Department of Cardiovascular and Thoracic Surgery, Stanford University School of Medicine, Stanford, Calif.

Dr Lai is a Carl and Leah McConnell Cardiovascular Surgical Research Fellow.

Read at the Twenty-eighth Annual Meeting of The Western Thoracic Surgical Association, Big Sky, Mont, June 19-22, 2002.

Received for publication June 30, 2002; revisions requested Oct 1, 2002; revisions received June 1, 2003; accepted for publication July 7, 2003.

Address for reprints: D. Craig Miller, MD, Department of Cardiothoracic Surgery, Falk Cardiovascular Research Center, Stanford University School of Medicine, Stanford, CA 94305-5247 (E-mail: dcm@ stanford.edu).

J Thorac Cardiovasc Surg 2003;126: 1978-86

Copyright $(\odot) 2003$ by The American Association for Thoracic Surgery

$0022-5223 / 2003 \$ 30.00+0$

doi:10.1016/S0022-5223(03)01279-0
Objective: To clarify the merits of various surgical approaches, we studied the outcome after composite valve graft versus separate valve and graft replacement versus conservative valve treatment with replacement of the ascending aorta in patients with acute type A aortic dissection complicated by aortic regurgitation.

Methods: Between 1967 and 1999, 123 patients (mean age $56 \pm 15$ years) underwent composite valve graft replacement $(n=21)$, separate valve and graft replacement $(\mathrm{n}=20)$, or conservative valve treatment $(\mathrm{n}=82$ [commissural resuspension in 46]); follow-up averaged 6.5 years (95\% complete).

Results: The 30-day, 1-year, and 6-year survival estimates of $85 \% \pm 4 \%, 79 \% \pm 5 \%$, and $69 \% \pm 5 \%$ ( \pm 1 standard error of mean), respectively, after conservative valve treatment were similar to $86 \% \pm 8 \%, 81 \% \pm 9 \%$, and $65 \% \pm 16 \%$, respectively, with composite valve graft replacement and better (but insignificantly so) than $70 \% \pm 10 \%$, $70 \% \pm 10 \%$, and $45 \% \pm 11 \%$, respectively, with separate valve and graft replacement. The 6-year freedom from proximal reoperation was $95 \% \pm 3 \%, 89 \% \pm 10 \%$, and $100 \%$ in conservative valve graft, separate valve and graft, and composite valve graft subgroups, respectively ( $P=$ not significant). Cox regression multivariable analysis identified that previous sternotomy (hazard ratio [or $\left.e^{\beta}\right]$ 95\% confidence interval 1.4-10.9, $P$ $=.006)$, hypertension $(0.99-2.9, P=.05)$, cardiac tamponade $(1.1-4.0, P=.03)$, and stroke (1.7-7.0, $P=.001)$ increased the hazard of death. No factors predicting a higher likelihood of late proximal reoperation were identified.

Conclusions: In patients with acute type A aortic dissection and aortic regurgitation, there was no significant difference in overall survival or reoperation rates among these surgical approaches. We try to save the valve whenever possible unless the aortic root is pathologically dilated (eg, Marfan syndrome or annuloaortic ectasia) or destroyed by the dissection process, when composite valve graft or valve-sparing aortic root replacement is indicated.

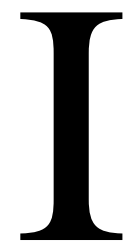

$\mathrm{n}$ treating patients with acute dissection of the aortic root complicated by aortic regurgitation (AR), the choice between composite valve graft (CVG) or valve-sparing aortic root replacement and conservative procedures (repair of the aortic root with conservation of the aortic valve and sinuses) (CONS) is largely dictated by operative findings, patient characteristics, and surgeon preference. A prospective, randomized, controlled trial to elucidate the relative merits of radical versus conservative surgical treatment of the 


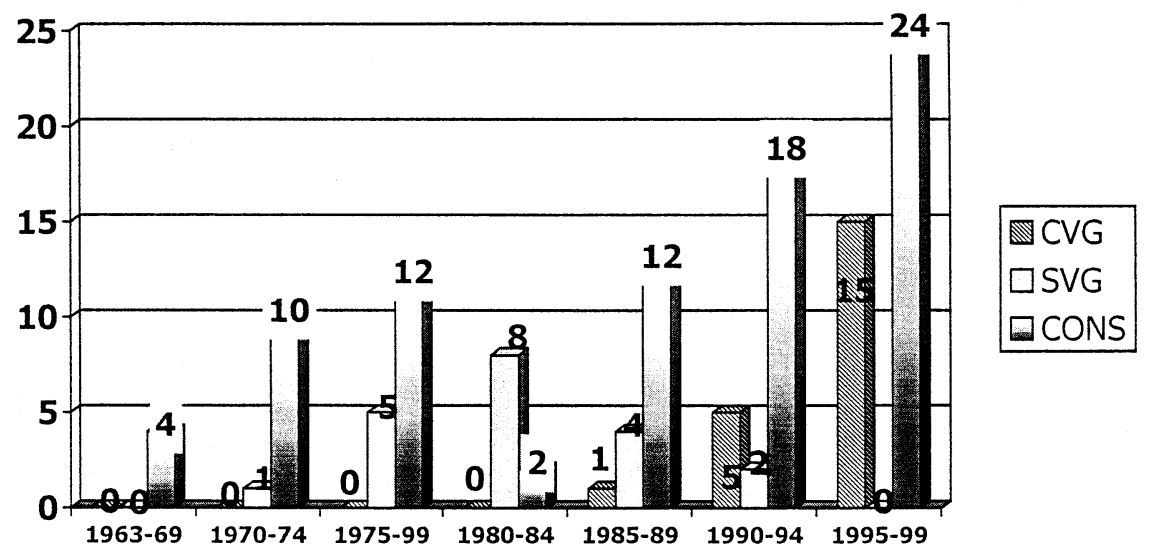

Figure 1. Patient distribution by year according to aortic root treatment method.

dissected aortic root is logistically impractical; instead, retrospective studies may serve to elucidate the best patient and pathoanatomic substrate amenable to a conservative versus a more aggressive approach to the aortic root and thus refine our surgical decision-making process. We therefore analyzed the outcome of CVG replacement of the aortic root versus subtotal aortic replacement with separate aortic valve and graft (SVG) versus CONS valve treatment with graft replacement of only the tubular segment of the ascending aorta in patients with type A aortic dissection complicated by AR.

\section{Methods \\ Patient Population}

The cardiovascular surgery database at Stanford University School of Medicine contained 307 consecutive patients who underwent surgery for spontaneous acute type A aortic dissection from January 1967 to July 1999. Of these, 123 patients had more than trivial AR and underwent aortic root reconstruction or replacement. Three treatment groups were defined: Twenty-one patients (17\%) were repaired using a CVG from 1989 to 1999,20 patients (16\%) were repaired using an SVG from 1972 to 1992, and 82 patients $(67 \%)$ were repaired by replacement of the ascending aorta and aortic valve conservation from 1967 to 1999 (CONS) (Figure 1). Within the CONS group, simple commissural resuspension was performed in 46 patients. The diagnosis was made by aortography, computed tomography, magnetic resonance imaging, transthoracic or transesophageal echocardiography, or surgical findings. Patient clinical characteristics are detailed in Appendix 1. Surgeons were categorized by experience as "high volume," those who performed 30 or more surgical repairs for aortic dissection (5 of 16 surgeons), and "low volume," those who performed 30 or less repairs (11 surgeons) (Appendix 1). The heterogeneous treatment groups reflected inherent patient selection and surgeon biases.

\section{Definitions}

The dissection was classified according to the 1970 Stanford system. ${ }^{1}$ The average time lapse from symptom onset to operation was $48 \pm 62$ hours. There was no difference in disease acuity among the treatment groups. Patients with type A intramural hematoma were also included (Appendix 1). AR was diagnosed by preoperative echocardiography or aortography.

\section{Operative Methods}

Although variability in surgical techniques was present among the individual surgeons and the surgical techniques evolved over the years, the surgical approach uniformly was to resect all of the tubular portion of the ascending aorta and, if identified, the primary intimal tear. Earlier, cannulation of the femoral artery was used for cardiopulmonary bypass, but the right axillary artery became the preferred site for arterial cannulation in the late 1990s. ${ }^{2}$ In recent years, most surgeons have striven to avoid aortic crossclamping whenever possible, resecting the underside of the transverse aortic arch and performing an open distal "hemiarch" anastomosis using profound hypothermic $\left(20^{\circ} \mathrm{C}-25^{\circ} \mathrm{C}\right.$ bladder temperature) circulatory arrest. In the early $1990 \mathrm{~s}$, a brief period of retrograde cold blood cerebral perfusion during completion of the open distal anastomosis was used by some surgeons. When the circulatory arrest period is anticipated to be longer than $30 \mathrm{~min}$ utes, selective antegrade cerebral perfusion is now used by most surgeons. During antegrade reperfusion and rewarming, attention is then directed to the proximal aortic root.

The most commonly performed proximal aortic procedure was reconstructing the sinotubular junction circumferentially and tube graft replacement of the ascending aorta. The native aortic valve was preserved whenever feasible. The main technical features of valve resuspension included complete transection of the proximal aorta, obliteration of the proximal false lumen down to the level of the aortic annulus with a custom-tailored piece of Teflon (DuPont, Wilmington, Del) felt inside the false lumen, and resuspension of the aortic valve commissures with circumferential suture reconstruction of the aorta. $^{3}$ Frequently, this proximal cuff was reinforced by an external layer of Teflon felt. We have never relied solely on placing individual pledgeted mattress sutures at the tops of the commissures for this purpose. In the last 2 years, BioGlue (Cryolife, Inc, North West Kennesaw, Ga) has been used instead of Teflon felt. The graft size was based on the goal of restoring the sinotubular junction diameter to approximate the aortic annular 


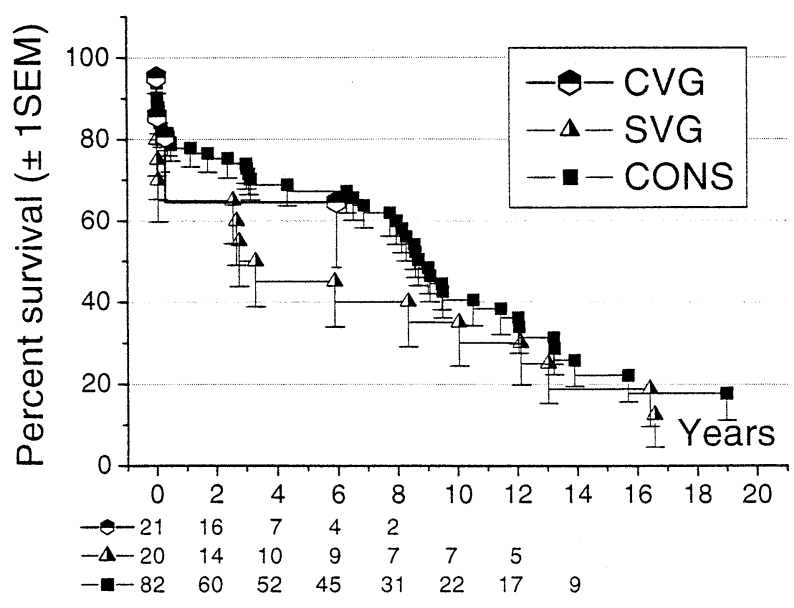

Figure 2. Actuarial survival estimates for all patients subdivided according to treatment group.

diameter. If attempts at commissural resuspension did not result in valvular competency, then aortic valve replacement using either the SVG or CVG approach was performed.

If the sinuses of Valsalva were excessively dilated (because of annuloaortic ectasia; $\mathrm{n}=15,71 \% \pm 10 \%$ of the $\mathrm{CVG}$ group $[70 \%$ confidence interval]), pathologically diseased (eg, the Marfan syndrome $[\mathrm{MFS}])$, or destroyed by the acute dissecting process $(\mathrm{n}=$ $3,15 \% \pm 8 \%$ of CVG) with or without irreparable compromise of the coronary arteries $(n=3,15 \% \pm 8 \%$ of $\mathrm{CVG})$, complete aortic root replacement was performed. If it was judged that valvular competency could not be satisfactorily restored or if severe valve pathology was present, valve replacement was performed. CVG replacement (mechanical valve $=20$; bioprosthetic valve $=1$ ) and reimplantation of the coronary ostia was always performed as an open procedure using Carrel coronary button anastomoses avoiding "wrap inclusion" (Bentall procedure).

In SVG procedures, the bulk of the sinuses of Valsalva were resected leaving small tongues of aortic root tissue surrounding the coronary ostia. After the aortic valve was excised, a mechanical (n $=1)$ or bioprosthetic $(\mathrm{n}=19)$ valve was inserted, and a woven synthetic graft was then anastomosed to the proximal and distal aortic cuffs (which were reinforced by 1 or more layers of Teflon felt). The extent of distal aortic resection in patients who underwent operation using hypothermic circulatory arrest and distribution of the location of the primary intimal tear are summarized in Appendix 1.

\section{Follow-up}

Current follow-up was obtained by telephone or written communication or both. Follow-up was $95 \%$ complete $(n=117)$, extended to a maximum of 30.7 years, and totaled 761 patient-years (Appendix 1).

\section{Postoperative Care}

Negative inotropic drug treatment was advised indefinitely, even in normotensive patients. ${ }^{4,5}$ Serial aortic surveillance with annual computed tomography or magnetic resonance imaging scans was also recommended, but compliance with this recommendation could not be ensured.

\section{Statistical Methods}

Outcomes. Valve-related complications have been detailed in a previous report. ${ }^{6}$ Time-related events studied included death at any time after operation and reoperation for proximal aortic complications. Freedom from these time-related events was estimated by the nonparametric actuarial Kaplan-Meier method. For freedom from reoperation, a nonfatal event, actual (or observed cumulative frequency) probabilities were also computed. Analyses stratified according to treatment modality were compared using the log-rank test. Early mortality was defined as death within 30 days of treatment or during the same hospitalization, regardless of time. The variability of continuous data is expressed as mean $\pm 1 \mathrm{SD}$, the variability of important fractions or ratios is expressed as $\pm 70 \%$ confidence levels (CL), and the variability of actuarial or actual estimates is expressed as \pm 1 SEM, approximately equivalent to $\pm 70 \% \mathrm{CL}$. Events arising from 1 or more valve-related complications were infrequent and thus were expressed as linearized rates (events per patient-year).

Identification of predictors of outcome. The influence of 25 preoperative characteristics or dissection-related complications (independent variables) on outcome (dependent variables) was analyzed by using SPSS for Windows (Release 10.0.0; SPSS Inc, Chicago, Ill). These independent variables included age, gender, duration of symptoms, year of operation, surgeon experience, shock, acute aortic insufficiency, paraplegia, visceral ischemia, renal dysfunction, peripheral pulse deficit, arch involvement, stroke, coronary artery disease, congestive heart failure, pulmonary disease, liver disease, diabetes mellitus, prior stroke, MFS, hypertension, previous dissection, previous sternotomy, tamponade, and rupture (Appendix 1). The predictors of time-related outcome were identified, and their hazard ratios (HR or $e^{\beta}$ ) with 95\% CL were determined from Cox proportional hazards analysis.

\section{Results}

\section{Survival}

For all patients, the 30-day, 1-year, and 6-year actuarial survival estimates were $85 \% \pm 4 \%, 78 \% \pm 5 \%$, and $65 \% \pm$ $5 \%$ ( \pm 1 SEM), respectively. There was no significant difference in overall survival between the 3 treatment groups: The 30-day, 1-year, and 6-year actuarial survival estimates, respectively, were $86 \% \pm 8 \%, 81 \% \pm 9 \%$, and $65 \% \pm 16 \%$ in the CVG group, $70 \% \pm 10 \%, 70 \% \pm 10 \%$, and $45 \% \pm$ $11 \%$ in the SVG group, and $85 \% \pm 4 \%, 79 \% \pm 5 \%$, and $69 \% \pm 5 \%( \pm 1 \mathrm{SE})$ in the CONS group (Figure 2$)$. The apparent lower survival estimates in the SVG group were not statistically significant. Risk factors for death at anytime included previous sternotomy $(\mathrm{n}=5$; multivariable HR 4.0, 95\% CL 1.5-10.9, $P=.006$; univariable HR 5.2, 95\% CL 2.0-13.6, $P=.001$ ), stroke (n $=12$; multivariable HR 3.3, 95\% CL 1.6-7.0, $P=.001$; univariable HR 2.8, 95\% CL $1.4-5.7, P=.005)$, cardiac tamponade $(\mathrm{n}=28$; multivariable HR 2.1, 95\% CL 1.1-4.0, $P=.03$; univariable HR 2.2, 95\% CL 1.2-4.3, $P=.01)$, and hypertension $(\mathrm{n}=65$, 
TABLE 1. Causes of late deaths subdivided according to proximal aortic root surgical treatment method

\begin{tabular}{|c|c|c|c|c|c|c|}
\hline & \multicolumn{2}{|c|}{ CVG } & \multicolumn{2}{|c|}{ SVG } & \multicolumn{2}{|c|}{ CONS } \\
\hline & $\mathbf{N}$ & $(\%)$ & $\mathbf{N}$ & (\%) & $\mathbf{N}$ & $(\%)$ \\
\hline Dissection rupture/extension & & & 1 & (2) & 10 & (12) \\
\hline Sudden, unexplained & & & 1 & (2) & & \\
\hline Arrhythmia & & & 2 & (4) & & \\
\hline Myocardial infarction & & & 1 & (2) & & \\
\hline Congestive heart failure & & & 1 & (2) & 7 & (9) \\
\hline Sepsis & 1 & (2) & & & & \\
\hline Renal failure & & & 1 & (2) & 3 & (4) \\
\hline Respiratory failure/pneumonia & & & 1 & (2) & 5 & (6) \\
\hline Stroke & & & 1 & (2) & 4 & (5) \\
\hline Anticoagulant hemorrhage & & & 1 & (2) & & \\
\hline Malignancy & & & & & 2 & (2) \\
\hline Suicide/accident & & & & & 1 & (1) \\
\hline Unknown & & & & & 2 & (2) \\
\hline
\end{tabular}

CVG, Composite valve graft; $S V G$, separate replacement of the aortic valve and ascending aorta; CONS, aortic valve conservation.

multivariable HR 1.7, 95\% CL 0.99-2.9, $P=.052$; univariable HR 1.9, 95\% CL 1.1-3.1, $P=.02$ ). Neither treatment method nor "high-volume surgeons" were associated with any difference in survival.

\section{Early Death}

The hazard of death was highest immediately after operation (Figure 2). There was no difference in early death rate among the treatment groups (Appendix 1). A Cox proportional hazards regression model showed that shock (HR 5.8; 95\% CL 1.5-23.4; $P=.01$ ) and stroke (HR 5.0; 95\% CL 1.2-20.0; $P=.02$ ) predicted a higher likelihood of early death.

\section{Late Death}

Death from aortic-related complications was defined as that caused by progression of dissection and/or rupture and those that were sudden and unexplained. The causes of late death are listed in Table 1. None of the patients in the CVG group died from an aortic-related complication; $2 \%$ of the patients in the SVG group and $15 \%$ of the patients in the CONS group could have possibly died as the result of an aortic complication. This raw fractional difference in cause of late deaths did not attain statistical significance. Stroke accounted for 5\% of late deaths in the CONS group and 2\% in the SVG group. Anticoagulant-related hemorrhage did not cause any late deaths in the CVG group but was responsible for $2 \%$ of late deaths in the SVG group. Comorbidities, such as congestive heart failure, accounted for a high proportion of late deaths in the CONS group relative to the CVG and SVG groups, but more patients with residual aortic valve regurgitation were not detected at follow-up in the CONS group. Sepsis led to 1 late death in the CVG group in the absence of evidence of endocarditis at autopsy.

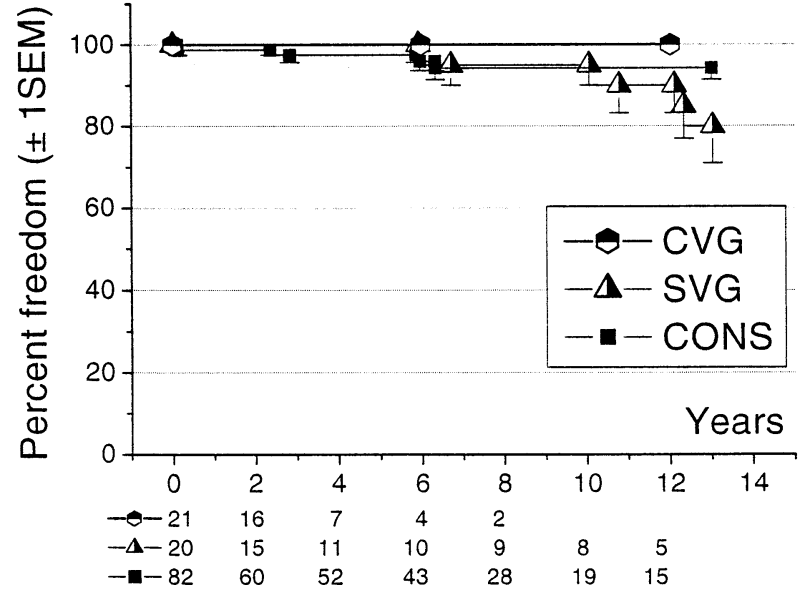

Figure 3. Actual freedom from proximal aortic reoperation estimates in all patients subdivided according to how the proximal aortic reconstruction was surgically performed.

\section{Proximal Aortic and Aortic Valve Reoperation}

The 6-year actuarial freedom from proximal aortic or aortic valve reoperation was $95 \% \pm 3 \%, 89 \% \pm 10 \%$, and $100 \%$ in the CONS, SVG, and CVG subgroups, respectively $(P=$ not significant [NS]). Specifically, the 6-year actuarial freedom estimates from proximal aortic reoperation were $99 \%$ $\pm 1 \%, 89 \% \pm 10 \%$, and $100 \% \pm 2 \%$ in the CONS, SVG, and CVG subgroups, respectively $(P=\mathrm{NS})$; the 6-year actuarial freedom estimates from aortic valve reoperation were $94 \% \pm 4 \%, 88 \% \pm 12 \%$, and $100 \% \pm 2 \%$, respectively $(P=\mathrm{NS})$. The 6-year actual freedom from proximal aortic or aortic valve reoperation was $98 \% \pm 1 \%, 95 \% \pm$ $1 \%$, and $100 \% \pm 2 \%$ in the CONS, SVG, and CVG groups, respectively, and did not differ significantly among any of the treatment groups (Figure 3). No risk factors predictive of proximal aortic or aortic valve reoperation could be identified, including MFS. Treatment method was not associated with any difference in the probability of proximal aortic or aortic valve reoperation.

\section{Major Morbidity and Valve-Related Complications}

There was no significant difference in the rate of early postoperative bleeding or neurologic complications among treatment methods (Appendix 1). The number of valverelated events was few, particularly in the CVG group; there also was no statistical difference in the linearized rate of valve-related complications (Table 2).

\section{Discussion}

In most patients presenting with acute type A aortic dissection complicated by AR, the aortic valve can be conserved by commissural resuspension and supracoronary aortic grafting. In most series, the number of repaired valves expressed as a percentage of total number of regurgitant 
TABLE 2. Linearized rates (\%/patient-year) of valve-related complications tabulated according to type of proximal surgical procedure performed

\begin{tabular}{|c|c|c|c|c|c|c|}
\hline & \multicolumn{2}{|c|}{ CVG } & \multicolumn{2}{|c|}{ SVG } & \multicolumn{2}{|c|}{ CONS } \\
\hline & $\mathbf{N}$ & Rate & $\mathbf{N}$ & Rate & $\mathbf{N}$ & Rate \\
\hline Residual valve disease & 0 & 0 & 3 & $2 \pm 3.1$ & 7 & $1.2 \pm 1.2$ \\
\hline Stroke & 0 & 0 & 2 & $1.3 \pm 2.5$ & 3 & $0.5 \pm 0.8$ \\
\hline Peripheral thromboembolism & 0 & 0 & 1 & $0.7 \pm 1.9$ & 0 & 0 \\
\hline Hemolysis & 0 & 0 & 0 & 0 & 0 & 0 \\
\hline \multicolumn{7}{|l|}{ Anticoagulant-related } \\
\hline Hemorrhage & 1 & $1.3 \pm 2.5$ & 0 & 0 & 0 & 0 \\
\hline Endocarditis & 0 & 0 & 0 & 0 & 1 & $0.2 \pm 0.5$ \\
\hline
\end{tabular}

Rate is events/100 patient-years, which is equivalent to $\% /$ patient-year ( $\pm 70 \%$ confidence limits).

valves ranged from $51 \%{ }^{6-9}$ to $100 \% .^{10}$ At Stanford, the aortic valve has been conserved in acute dissection with increasing frequency during the last decade (Figure 1): The fraction of leaking aortic valves repaired increased from $52 \% \pm 6 \%$ in a 19912 -center report ${ }^{6}$ (Duke University) to $67 \% \pm 4 \%$ in this present study. Despite our increased zeal for preservation of the aortic valve, the actuarial estimate of freedom from aortic valve reoperation is still high $(94 \% \pm$ $4 \%$ at 6 years) compared with the earlier Stanford-Duke estimate of $100 \%$ at 5 years. ${ }^{6}$ These results indicate that the surgeons over the years consistently adhered to fairly uniform anatomic and pathologic guidelines in terms of what procedure to perform. Patients with MFS, annuloectasia, and extensive aortic root dissection only rarely had the valve conserved, as other groups advocate. ${ }^{6,9-15}$ For example, Casselman and colleagues ${ }^{13}$ reported that an aortic valve annulus greater than $27 \mathrm{~mm}$ in diameter was associated with a 4.2-fold increase in relative risk of aortic root reoperation.

Contrary to our experience, the use of Teflon felt for reconstruction of the aortic root has not met with widespread uniform success. ${ }^{9,13,16}$ Niederhauser and colleagues ${ }^{9}$ reported that at 2 years, patients who underwent gelatinresorcin-formaldehyde (GRF) (or "French" glue) reconstruction of the aortic root had an increased freedom from reoperation on the aortic root $(92 \%$ vs $70 \%, P=.02)$ and event-free survival ( $77 \%$ vs $41 \%, P=.02$ ) compared with simple suture resuspension. Although we recognize the benefits of a tissue adhesive in creating a sturdy substrate for suturing and have moved to BioGlue as a substitute for Teflon felt, we remain dubious about GRF in light of recent reports of GRF-related tissue necrosis of the aortic root. ${ }^{17}$

Overall, supra-commissural aortic valve resuspension has exhibited relatively excellent long-term durability in this and other series. ${ }^{6-8,10,11,16,18}$ There is, however, 1 confounding factor: The reported long-term durability of the repair may artifactually be better when all patients are considered instead of just those with AR. ${ }^{8,11,18,19}$ Pessotto and coworkers ${ }^{7}$ and Mazzucotelli and coworkers ${ }^{11}$ reported that the presence of moderate-to-severe aortic insufficiency in patients portends an increased rate of reoperation (>37\%-39\% of patients) compared with patients with no or mild AR. Kirsch and colleagues from the Hôpital Henri Mondor $^{20}$ reported that severe AR increased the HR of reoperation on the proximal aorta by 3.6-fold (1.44-9.07; 95\% confidence interval) and recommended more frequent consideration of CVG (or valve-sparing aortic root replacement) at the time of the initial operation in patients with severe AR. We concur given that moderate-to-severe AR may be a surrogate for more pronounced aortic root disease.

Freedom from aortic root reoperation was independent of both surgical treatment method and patient-related risk factors. The MFS did not emerge as a risk factor for reoperation, as intuition would dictate, perhaps because most patients with MFS received a CVG procedure. The fact that this analysis was unable to identify factors predicting an increased likelihood of reoperation reflects appropriate patient selection for the various procedures, namely, customizing the operative procedure to the patient and his or her disease.

The actuarial estimate of freedom from reoperation in the SVG group was "artificially" lowered by the strong competing hazard of death; when expressed as an actual estimate, freedom from reoperation was comparable to that in the CONS and CVG groups (Figure 3). Nonetheless, we basically abandoned the SVG procedure in 1989 (Figure 1). Indeed, Moon and colleagues ${ }^{19}$ reported a very high operative mortality rate of $50 \% \pm 16 \%$ for patients undergoing SVG; however, similar to our findings, they found no difference in late aortic reoperation or survival depending on which aortic root operative technique was performed initially. Patient survival, including early postoperative mortality, also was not influenced by treatment method; it seems that patient substrate was the main determinant of survival, a finding corroborated by Niederhauser and colleagues. ${ }^{9}$ The predictors of short- and long-term survival were patient-related and dissection-related factors, which for the most part cannot readily be modified. There is some debate concerning whether long-term survival and operative mortality risk after either an aggressive or a more conservative 
aortic root procedure are comparable in centers with special thoracic aortic expertise. ${ }^{8,9,11,18,19}$ Ergin and coworkers ${ }^{21}$ from Mount Sinai reported that patients undergoing total root replacement represented a higher operative risk subset as the result of having substantial AR and coronary dissection, but paradoxically had substantially better event-free survival estimates at 5 years $(88 \% \pm 12 \%$ vs $67 \% \pm 9 \%)$ and 9 years $(88 \% \pm 22 \%$ vs $63 \% \pm 19 \%)$; these authors recommended that root replacement should be considered more frequently. On the other hand, data reported by Sabik and colleagues ${ }^{18}$ from the Cleveland Clinic showed that CVG carried a significant adverse impact on overall survival $(P=.0009)$, primarily in the early hazard phase. von Segesser and coworkers ${ }^{8}$ have argued that simple preservation of the valve offers a sound long-term prognosis without exposing the patient to undue risk. The general consensus today ${ }^{6-8,13-15,18-20,22}$ indicates that a more aggressive surgical approach (eg, CVG) should be considered only in special circumstances.

The David "reimplantation" 23 or Yacoub "remodeling" 24 methods of valve-sparing aortic root replacement combined the benefits of aortic root replacement as well as preservation of the aortic valve; thus, this may be an even better alternative for repair of the dissected aortic root in highly selected patients with an acute type A aortic dissection and AR. The early results reported by Graeter and colleagues from Homburg, ${ }^{25}$ Leyh and colleagues ${ }^{26}$ from Lubeck, and the cardiovascular surgical group from Hannover ${ }^{27}$ have been encouraging. The outcome after CVG and CONS procedures reported in this article will serve as clinical benchmarks in the future to assess the putative long-term benefits of this "ultraradical" valve-sparing surgical approach as applied to these very challenging patients.

\section{Limitations}

The current study was limited by the absence of universal follow-up echocardiographic data; it is therefore highly likely that the freedom from aortic valve reintervention rate was underestimated by some patients having moderate or possibly even severe AR yet not having undergone reoperation. We were unable to demonstrate any long-term benefit or drawbacks associated with repairing the native aortic valve compared with replacement with either a mechanical or a biologic valve substitute in terms of structural and nonstructural valve failure, anticoagulant-related hemorrhage, endocarditis, or thromboembolic events, but because late attrition was high and serial echocardiographic surveillance was incomplete, this may be attributable to inadequate statistical power.

Acute AR was present in only 123 of 307 patients (40\%), which is less than the 59\% and 100\% reported by Ehrlich and coworkers ${ }^{28}$ and Niederhauser and coworkers, respectively. ${ }^{9}$ This discrepancy is probably attributable to different methods for classifying the severity of acute AR rather than the acuity of disease. A possible selection bias may have been introduced by excluding 28 patients in the CVG and SVG groups who did not have AR preoperatively; analysis of all 307 patients with or without AR did not change the major conclusions, but SVG was associated with a higher probability of proximal aortic reoperation.

\section{Conclusion}

There was no significant difference in overall survival or proximal reoperation rates after either an aggressive or a conservative operation for patients with acute type A aortic dissection. We concur with the editorial philosophies espoused recently by Elefteriades ${ }^{14}$ and $\mathrm{Kron}^{22}$ that the best operation is one that is customized to each individual patient. We presently prefer CONS, CVG, or David reimplantation valve-sparing aortic root replacement depending on the individual patient and specific pathoanatomic features encountered.

\section{References}

1. Daily PO, Trueblood HW, Stinson EB, et al. Management of acute aortic dissections. Ann Thorac Surg. 1970;10:237-47.

2. Sabik JF, Lytle BW, McCarthy PM, et al. Axillary artery: an alternative site of arterial cannulation for patients with extensive aortic and peripheral vascular disease. J Thorac Cardiovasc Surg. 1995;109:88590.

3. Moon MR, Miller DC. Aortic arch replacement for dissection. OpTechs Thorac Cardiovasc Surg. 1999;4:33-57.

4. Miller DC, Mitchell RS, Oyer PE, et al. Independent determinants of operative mortality for patients with aortic dissections. Circulation. 1984;70(3 Pt 2):I153-64.

5. Svensson LG, Crawford ES, Hess KR, et al. Variables predictive of outcome in 832 patients undergoing repairs of the descending thoracic aorta. Chest. 1993;104:1248-53.

6. Fann JI, Glower DD, Miller DC, et al. Preservation of aortic valve in type A aortic dissection complicated by aortic regurgitation. $J$ Thorac Cardiovasc Surg. 1991;102:62-73.

7. Pessotto R, Santini F, Pugliese P, et al. Preservation of the aortic valve in acute type A dissection complicated by aortic regurgitation. Ann Thorac Surg. 1999;67:2010-3.

8. von Segesser LK, Lorenzetti E, Lachat M, et al. Aortic valve preservation in acute type A dissection: is it sound? J Thorac Cardiovasc Surg. 1996;111:381-90.

9. Niederhauser U, Kunzli A, Seifert B, et al. Conservative treatment of the aortic root in acute type A dissection. Eur J Cardiothorac Surg. 1999; 15:557-63.

10. Westaby S, Katsumata T, Freitas E. Aortic valve conservation in acute type A dissection. Ann Thorac Surg. 1997;64:1108-12.

11. Mazzucotelli JP, Deleuze PH, Baufreton C, et al. Preservation of the aortic valve in acute aortic dissection: long-term echocardiographic assessment and clinical outcome. Ann Thorac Surg. 1993;55:1513-7.

12. Santini F, Pessotto R, Restivo S, et al. Factors influencing outcome after emergency surgical repair of acute type A aortic dissection. G Ital Cardiol. 1999;29:1015-9.

13. Casselman FP, Tan ES, Vermeulen FE, et al. Durability of aortic valve preservation and root reconstruction in acute type A aortic dissection. Ann Thorac Surg. 2000;70:1227-33.

14. Elefteriades JA. What operation for acute type A dissection? J Thorac Cardiovasc Surg. 2002;123:201-3.

15. Bachet J. Acute type A aortic dissection: can we dramatically reduce the surgical mortality? Ann Thorac Surg. 2002;73:701-3.

16. Bachet J, Goudot B, Dreyfus GD, et al. Surgery for acute type A aortic dissection: the Hopital Foch experience (1977-1998). Ann Thorac Surg. 1999;67:2006-9. 
17. Fukunaga S, Karck M, Harringer W, et al. The use of gelatin-resorcinformalin glue in acute aortic dissection type A. Eur J Cardiothorac Surg. 1999;15:564-9.

18. Sabik JF, Lytle BW, Blackstone EH, et al. Long-term effectiveness of operations for ascending aortic dissections. J Thorac Cardiovasc Surg. 2000;119:946-62.

19. Moon MR, Sundt TM III, Pasque MK, et al. Does the extent of proximal or distal resection influence outcome for type A dissections? Ann Thorac Surg. 2001;71:1244-9.

20. Kirsch M, Soustelle C, Houel R, et al. Risk factor analysis for proximal and distal reoperations after surgery for acute type A aortic dissection. J Thorac Cardiovasc Surg. 2002;123:318-25.

21. Ergin MA, McCullough J, Galla JD, et al. Radical replacement of the aortic root in acute type A dissection: indications and outcome. Eur J Cardiothorac Surg. 1996;10:840-4.

22. Kron IL. Editorial regarding "Does the extent of proximal or distal resection influence outcome for type A dissections?." Ann Thorac Surg. 2001;71:1249-50.
23. David TE, Feindel CM, Bos J. Repair of the aortic valve in patients with aortic insufficiency and aortic root aneurysm. J Thorac Cardiovasc Surg. 1995;109:345-51.

24. Sarsam MA, Yacoub M. Remodeling of the aortic valve anulus. J Thorac Cardiovasc Surg. 1993;105:435-8.

25. Graeter TP, Langer F, Nikoloudakis N, et al. Valve-preserving operation in acute aortic dissection type A. Ann Thorac Surg. 2000;70: 1460-5.

26. Leyh RG, Schmidtke C, Bartels C, et al. Valve-sparing aortic root replacement (remodeling/reimplantation) in acute type A dissection. Ann Thorac Surg. 2000;70:21-4.

27. Leyh RG, Fischer S, Kallenbach K, et al. High failure rate after valve-sparing aortic root replacement using the "remodeling technique" in acute type A aortic dissection. Circulation. 2002;106(12 Suppl 1):I229-33.

28. Ehrlich MP, Ergin MA, McCullough JN, et al. Results of immediate surgical treatment of all acute type A dissections. Circulation. 2000; 102(19 Suppl 3):III248-52.

APPENDIX 1. Characteristics of 123 patients with acute type A aortic dissection complicated by aortic regurgitation, subdivided into those repaired using composite valve grafting, separate aortic and valve graft replacement, or aortic valve conservation

\begin{tabular}{|c|c|c|c|c|c|c|c|c|}
\hline & \multicolumn{2}{|c|}{$\begin{array}{l}\text { All patients } \\
\text { (n = 123) }\end{array}$} & \multicolumn{2}{|c|}{$\begin{array}{c}\text { CVG } \\
(n=21)\end{array}$} & \multicolumn{2}{|c|}{$\begin{array}{c}\text { SVG } \\
(n=20)\end{array}$} & \multicolumn{2}{|c|}{$\begin{array}{c}\text { CONS } \\
(\mathrm{n}=82)\end{array}$} \\
\hline & $\mathbf{N}$ & (\%) & $\mathbf{N}$ & $(\%)$ & $\mathbf{N}$ & $(\%)$ & $\mathbf{N}$ & (\%) \\
\hline \multicolumn{9}{|l|}{ Demographics } \\
\hline Age (mean $\pm S D)(y r)$ & $56 \pm 15$ & & $51 \pm 19^{*}$ & & $51 \pm 15^{*}$ & & $59 \pm 13^{*}$ & \\
\hline Gender & & & & & & & & \\
\hline Male & 84 & (68) & 15 & (71) & 15 & (75) & 54 & (66) \\
\hline Female & 39 & (32) & 6 & (29) & 5 & (25) & 28 & (34) \\
\hline Surgeon experience & 100 & (81) & 20 & $(95)^{* *}$ & 10 & $(50)^{* *}$ & 70 & $(85)^{* *}$ \\
\hline \multicolumn{9}{|l|}{ Presentation } \\
\hline Duration of symptoms (hrs) & $48 \pm 62$ & & $40 \pm 39$ & & $45 \pm 47$ & & $51 \pm 70$ & \\
\hline Year of operation & $1987 \pm 9$ & & $1996 \pm 3^{* *}$ & & $1982 \pm 5^{* *}$ & & $1986 \pm 10^{* *}$ & \\
\hline Year of operation (range) & 1967-1999 & & 1989-1999 & & 1973-1992 & & 1967-1999 & \\
\hline Shock & 12 & (10) & 2 & (10) & 2 & (10) & 8 & (10) \\
\hline Paraplegia & 3 & (2) & 0 & (0) & 0 & (0) & 3 & (4) \\
\hline Visceral ischemia & 0 & (0) & 0 & (0) & 0 & (0) & 0 & (0) \\
\hline Renal dysfunction & 25 & (20) & 0 & $(0)^{*}$ & 6 & $(30)^{*}$ & 19 & $(23)^{*}$ \\
\hline Peripheral pulse deficit & 58 & (47) & 5 & (24) & 11 & (55) & 42 & (51) \\
\hline \multicolumn{9}{|l|}{ Extent of dissection } \\
\hline Ascending aorta & 14 & (11) & 2 & (10) & 2 & (10) & 10 & (12) \\
\hline Asc Ao + Arch & 18 & (15) & 4 & (19) & 4 & (20) & 10 & (12) \\
\hline Asc Ao + Arch + Dsc Thor Ao & 28 & (23) & 4 & (19) & 2 & (10) & 22 & (27) \\
\hline Asc Ao + Arch + Dsc Thor Ao + Abd Ao & 63 & (51) & 11 & (52) & 12 & (60) & 40 & (49) \\
\hline Intramural hematoma & 1 & (1) & 0 & (0) & 0 & (0) & 1 & (1) \\
\hline Stroke & 12 & (10) & 1 & (5) & 1 & (5) & 10 & (12) \\
\hline \multicolumn{9}{|l|}{ Associated conditions } \\
\hline CAD & 31 & (25) & 6 & (29) & 3 & (15) & 22 & (27) \\
\hline $\mathrm{CHF}$ & 10 & (8) & 1 & (5) & 1 & (5) & 8 & (10) \\
\hline Pulmonary disease & 27 & (9) & 12 & (6) & 15 & (12) & 15 & (12) \\
\hline Liver disease & 5 & (4) & 0 & (0) & 1 & (5) & 4 & (5) \\
\hline Diabetes mellitus & 7 & (6) & 2 & (10) & 1 & (5) & 4 & (5) \\
\hline Prior stroke & 7 & (6) & 0 & (0) & 0 & (0) & 7 & (9) \\
\hline Marfan syndrome & 14 & (11) & 8 & $(38)^{* *}$ & 3 & $(15)^{* *}$ & 3 & $(4)^{* *}$ \\
\hline Hypertension & 65 & (53) & 8 & $(38)^{*}$ & 7 & $(35)^{*}$ & 50 & $(61)^{*}$ \\
\hline Previous aortic dissection & 2 & (2) & 2 & $(10)^{* *}$ & 0 & $(0)^{* *}$ & 0 & $(0)^{* *}$ \\
\hline Previous sternotomy & 5 & (4) & 1 & (5) & 0 & (0) & 4 & (5) \\
\hline
\end{tabular}




\section{APPENDIX 1. Continued}

\begin{tabular}{|c|c|c|c|c|c|c|c|c|}
\hline & \multicolumn{2}{|c|}{$\begin{array}{l}\text { All patients } \\
(\mathrm{n}=123)\end{array}$} & \multicolumn{2}{|c|}{$\begin{array}{c}\text { CVG } \\
(n=21)\end{array}$} & \multicolumn{2}{|c|}{$\begin{array}{c}\text { SVG } \\
(n=20)\end{array}$} & \multicolumn{2}{|c|}{$\begin{array}{c}\text { CONS } \\
(n=82)\end{array}$} \\
\hline & $\mathbf{N}$ & $(\%)$ & $\mathbf{N}$ & $(\%)$ & $\mathbf{N}$ & $(\%)$ & $\mathbf{N}$ & $(\%)$ \\
\hline \multicolumn{9}{|l|}{ Operative findings } \\
\hline Tamponade & 28 & (23) & 7 & (33) & 2 & (10) & 19 & (23) \\
\hline Aortic rupture & 57 & (46) & 10 & (48) & 8 & (40) & 39 & (48) \\
\hline \multicolumn{9}{|l|}{ Site of PIT } \\
\hline Asc Ao & 107 & (87) & 19 & (91) & 18 & (90) & 70 & (85) \\
\hline Arch & 8 & (7) & 0 & (0) & 2 & (10) & 6 & (7) \\
\hline Dsc Thor Ao & 3 & (2) & 1 & (5) & 0 & $(0)$ & 2 & (2) \\
\hline Unknown & 5 & (4) & 1 & (5) & 0 & (0) & 4 & (5) \\
\hline Arch resection & 24 & (20) & 10 & $(48)^{* *}$ & 0 & $(0)^{* *}$ & 14 & $(17)^{* *}$ \\
\hline Resection of PIT & 111 & (90) & 18 & (86) & 18 & (90) & 75 & (92) \\
\hline Aortic crossclamp time (min) & $90 \pm 42$ & & $143 \pm 38^{* *}$ & & $106 \pm 45^{* *}$ & & $72 \pm 26^{* *}$ & \\
\hline Cardiopulmonary bypass time (min) & $147 \pm 63$ & & $216 \pm 64^{* *}$ & & $157 \pm 66^{* *}$ & & $127 \pm 48^{* *}$ & \\
\hline Coronary artery bypass graft & 11 & $(16)$ & 0 & (0) & 5 & (25) & 6 & (12) \\
\hline \multicolumn{9}{|l|}{ Postoperative complications } \\
\hline Bleeding & 13 & (11) & 3 & (15) & 3 & (18) & 7 & (9) \\
\hline Stroke & 13 & (11) & 1 & (5) & 3 & (16) & 9 & $(12)$ \\
\hline \multicolumn{9}{|l|}{ Follow-up } \\
\hline Follow-up period & $6.5 \pm 6.1$ & & $3.7 \pm 3.0$ & & $7.6 \pm 7.6$ & & $7.0 \pm 6.2$ & \\
\hline Early death & 20 & $(16 \pm 3.3)$ & 3 & $(14 \pm 7.8)$ & 6 & $(30 \pm 11)$ & 11 & $(13 \pm 3.8)$ \\
\hline
\end{tabular}

CVG, Composite valve graft; SVG, separate replacement of the aortic valve and ascending aorta; CONS, aortic valve conservation; visceral ischemia, compromised arterial perfusion of anyintra-abdominal organ diagnosed by angiography or computed tomography or magnetic resonance imaging; renal dysfunction, compromised renal perfusion by angiography, acute anuria, renal infarction, or serum creatinine $\geq 3$ or blood urea nitrogen $\geq 40$; peripheral pulse deficit, loss of blood flow to extremities as documented by physical examination, angiography, or computed tomography, Asc Ao, ascending aorta; Dsc Thor Ao, descending thoracic aorta; Abd Ao, abdominal aorta; $C A D$, coronary artery disease as indicated by a previous diagnosis of coronary disease or myocardial ischemia or infarction; $C H F$, congestive heart failure; pulmonary disease, diagnosis of chronic obstructive pulmonary disease or significant lung ailment; liver disease, total bilirubin $>2.0$ at the time of diagnosis; prior stroke, history of strokes or transient ischemic attacks; aortic rupture, presence of blood in the pericardial cavity; site of PIT, site of primary intimal tear diagnosed either on preoperative imaging or at operation; surgeon experience, "high-volume" surgeons who performed 30 or more surgical repairs for aortic dissection (comprising 5 of 16 surgeons in the database) versus 11 "low-volume" surgeons who performed 30 or less repairs; bleeding, postoperative hemorrhage requiring reoperation. ${ }^{*} P<.05$; ${ }^{* *} P<.01$ by either $\chi^{2}$ test or analysis of variance.

\section{Discussion}

Dr H. Storm Floten (Portland, Ore). For their continued fine work in the management of acute type A dissection, I commend Dr Lai, Dr Miller, and their associates at Stanford University. Acute type A dissection is a condition that still tightens the sphincters of the best of heart surgeons and still bears an early operative mortality rate in the neighborhood of $25 \%$. In their article they give a flawless statistical analysis comparing 3 standard methods of dealing with acute dissection of the root and aortic insufficiency. They show that there is no statistical difference in the early or late survival or in the reoperation rate for the 3 methods. Factors affecting morality were reoperation, hypertension, tamponade, and stroke. The highest risk of death was immediately after surgery, and early death was predicted by shock and prior stroke. At the Starr-Wood cardiac group and the Oregon Health Sciences University in Portland, we have adopted much of the same philosophies as Stanford in the management of this condition. Most cases involve valve repair or composite graft repair when we encounter MFS, annular ectasia, or dilated root. We have not used separate valve replacement and sleeve graft in saving the sinuses. Our philosophy has been that if we cannot save the valve, why save the sinuses that are the primary problem? This leaves the operative decision largely between the 2 techniques of composite graft or valve repair. Frankly, we find that in a normal-sized aorta the commissural resuspension and sinus repair is an easier procedure, and we are comforted by the report indicating that we may be doing the right thing. The conduit procedure is easier when encountering MFS, a dilated aorta, or annular ectasia. The most difficult cases are when there is a normal-sized root or small root that has massive dissection, maybe all 3 sinuses, and, in particular, when I see staining of blood south of the annulus down into the endocardium and myocardium. These cases are going to really require a conduit graft in my experience to avoid valve incompetence and sinus rupture. We have not been able to consistently duplicate the valve-preserving root-replacement procedures of David and Yakoub, and I am reluctant to embrace their operations for acute pathology that we are discussing today. Your techniques at Stanford are hallmark to the success in management of acute dissection. Complete resection of the aorta above the sinotubular junction facilitated by profound hypothermia, no crossclamp, open anastomosis at the arch and beyond, retrograde cerebral perfusion, and selective antegrade perfusion are all critical techniques to be used. We still repair the root with Teflon felt in the false lumen of the sinuses and resuspend the aortic commissures. In addition, we turn the adventitia in over the top of the felt to thereby circumferentially reconstruct the aortic root. 